\title{
Avaliação de temas de educação ambiental nos livros de química do plano nacional do livro didático
}

\author{
Evaluation of Environmental Education Themes in Chemistry Books of the Textbook National Plan (PNLD) \\ Eduardo Giuliani Koehler', Martha Bohrer Adaime², Miguel Antonio Correa Favila² \\ ' Colégio Militar de Santa Maria, Santa Maria, Brasil. \\ ${ }^{2}$ Doutores, Universidade Federal de Santa Maria, Santa Maria, Brasil.
}

\begin{abstract}
Resumo
A preocupação com questões ambientais, gera discussões nas diferentes esferas de ensino e nos meios de comunicação, os quais alertam constantemente para os problemas ambientais, mudanças climáticas e catástrofes. A Educação Ambiental (EA) deve ser trabalhada no Ensino Médio como um tema transveral contribuindo para que o estudante tenha uma maior compreensão sobre problemas ambientais tão difundidos no cotidiano atual. Dessa forma, este trabalho teve o objetivo de avaliar os livros didáticos de Química indicados pelo Plano Nacional do Livro Didático (PNLD) do triênio 2012-2014, em relação à temática de EA e a sua pertinência no Ensino Médio. Os assuntos avaliados foram: (i) uso de clorofluorcabonetos e camada de ozônio; (ii) efeito estufa e aquecimento global; (iii) chuva ácida e água: poluição e tratamento.Foram criadas três categorias de análise com o objetivo de direcionar a pesquisa nos pontos relevantes para o conhecimento químico a ser trabalhado em sala de aula. As três categorias são: (i) explicação teórica do assunto; (ii) compreensão do assunto e (iii) exercícios propostos. De acordo com a análise, observou-se que os livros de Química do PNLD se mostram adequados para a práticas de tais temáticas quando trabalhadas na sala de aula relacionadas aos conteúdos de Química.
\end{abstract}

Palavras-chaves: Educação Ambiental; Análise de Livros Didáticos; Livros PNLD.

\begin{abstract}
The concern about environmental issues has generated discussions in different teaching levels and also on the media, which constantly alert for the environmental problems, climate change and catastrophies. Environmental Education (EE) must be worked with in high school as a transversal theme, helping the student to have a broader comprehension about the environmental problems which have been so much discussed nowadays. Thus, this work aims to evaluate the chemistry textbooks suggested by the Textbook National Plan (PNLD) of the period 2012-2014, in terms of the Environmental Education theme and its appropriateness in high school. The subjects evaluated were the following: (i) use of chlorofluorocarbons and ozone layer; (ii) greenhouse effect and global warming; (iii) acid rain and water: pollution and treatment. Three categories of analysis were devised, aiming to guide the research in the most relevant aspects for the chemistry knowledge to be studied in classroom. The three categories are: (i) theoretical explanation of the subject; (ii) comprehension of the subject and (iii) exercises suggested. According to the analysis, it was observed that the chemistry PNLD textbooks are adequate for the practice of such themes when studied in classroom in relation to the chemistry contents.
\end{abstract}

Keywords: Environmental Education; TextbooksAnalysis; PNLD books. 


\section{INTRODUÇÃO}

O livro didático (LD), atualmente é uma ferramenta de grande importância dentro das escolas, pois apresenta o conteúdo de uma forma ordenada pelo grau de complexidade, seguindo um critério do autor.Nas escolas a utilização do LD deve ser feita de forma planejada e discutida entre docentes, pois o LD apresenta um caráter pedagógico, sendo um instrumento para o professor (MIRANDA e LUCA, 2004), apresenta o conhecimento tanto para quem ensina, quanto para quem aprende, não é completo e não contém todas as respostas e o conteúdo apresentado serve para direcionar o trabalho do docente. O trabalho docente com base no LD apresenta importância diferenciada de acordo com o lugar, as condições e situações com que é produzido (FRIZON et al, 2009) ou seja, a escolha deve levar em consideração a abordagem dos assuntos, bem como a linguagem utilizada pelo autor, se esta é compatível com o nível dos discentes. Este fato se confirma ainda mais com base nos Parâmetros Curriculares Nacionais os PCNs, em que há a recomendação de que o professor utilize em sala de aula além do livro didático, materiais diversificados (jornais, revistas, computadores, filmes, etc), como fontes de informação, de forma a ampliar o tratamento dado aos conteúdos e fazer com que o aluno sinta-se inserido no mundo à sua volta. A importância desta escolha, também está fundamentada no fato de que para muitos brasileiros, o LD é o primeiro livro, que abre caminho para o gosto pela leitura e para o aprendizado (EDUCAÇÃO NA MÍDIA, 2013). Embora atualmente existam outras formas de acesso ao conteúdo teórico, decorrentes dos avanços tecnológicos, entre eles: mapas, enciclopédias, audiovisuais, softwares didáticos, CD-ROM, Internet, dentre outros,ainda assim o LD continua ocupando um papel central (RODRIGUES \& FREITAS, 2008), se tornando para o aluno um dos elementos determinantes de sua relação e interação com a disciplina. Existem no Brasil, programas do governo federal para auxiliar as escolas na obtenção de LD, o Programa Nacional do Livro Didático (PNLD) criado a partir do decreto n. 91.542, de 19 de agosto de 1985, que propõe a indicação do livro didático pelo professor e a reutilização do livro, resultando na abolição do livro descartável (MANTOVANI, 2009). Esta escolha é realizada a partir do GUIA DO LIVRO DIDÁTICO, com o qual os professores podem selecionar os livros para serem trabalhados em um período de três anos (MAIA et al, 2009). A importância de se fazer uma análise eficiente é fundamental, pois de acordo com Cursino,et al (2008) :"a questão dos livros didáticos para o ensino de Química constitui uma preocupação constante de pesquisa, sendo que alguns estudos mostram como um processo acrítico repetitivo leva à transmissão de muitos erros conceituais de livros, deles para os professores e desses para os alunos".

\section{MATERIAIS E MÉTODOS}

De acordo dom o Guia do Livro Didático das 19 coleções inscritas para o programa, apenas 5 foram classificadas e distribuídas nas escolas cadastradas a partir de 2012, que para melhor análise sobre os temas de Educação Ambiental (EA), serão caracterizadas como A, B, C, D e E, ilustradas no Quadro 1.

Quadro 1: Livros do PNLD - triênio 2012 - 2014.

\begin{tabular}{|l|l|l|l|}
\hline LD & \multicolumn{1}{|c|}{ Título } & \multicolumn{1}{c|}{ Autor(es) } & Editora \\
\hline A & $\begin{array}{l}\text { Química na Abordagem } \\
\text { do Cotidiano. }\end{array}$ & $\begin{array}{l}\text { Eduardo Leite do Canto e } \\
\text { Francisco Miragaia Peruzzo }\end{array}$ & $\begin{array}{l}\text { Moderna } \\
4^{\mathrm{a}} \text { edição, 2010 }\end{array}$ \\
\hline B & $\begin{array}{l}\text { Química - Meio ambiente - } \\
\text { Cidadania - Tecnologia }\end{array}$ & Martha Reis & $\begin{array}{l}\text { FTD } \\
1^{\mathrm{a}} \text { edição, 2010 }\end{array}$ \\
\hline C & Química & $\begin{array}{l}\text { Andréa Horta Machado e } \\
\text { Eduardo Fleury Mortimer }\end{array}$ & $\begin{array}{l}\text { Scipione } \\
1^{\mathrm{a}} \text { edição, 2011 }\end{array}$ \\
\hline D & $\begin{array}{l}\text { Química Para a Nova Geração } \\
\text { - Química Cidadã }\end{array}$ & $\begin{array}{l}\text { Wildson Santos e Gerson Mól } \\
\text { (Coordenadores) }\end{array}$ & $\begin{array}{l}\text { Nova Geração } \\
1^{\mathrm{a}} \text { edição, 2010 }\end{array}$ \\
\hline E & Ser Protagonista - Química & Júlio Cézar Foschini Lisboa & $\begin{array}{l}\text { Edições SM } \\
1^{\mathrm{a}} \text { edição, 2010 }\end{array}$ \\
\hline
\end{tabular}

A temática ambiental surge a partir de uma reflexão social de um meio cada vez mais degradado (JACOBI, 2003) tanto que a UNESCO (Organização das Nações Unidas para a Educação, a Ciência e a Cultura) desde 
1973, destaca a importância de pesquisas que venham a contribuir com o melhor planejamento sobre o meio ambiente. Embora amparada em leis que convergem para a prática ambiental nas escolas, muitas vezes, ocorre o contrário, educandos e professores ficam restritos aos conteúdos programáticos deixando assuntos ambientais em segundo plano (CUBA, 2010). Diante do exposto, a presente pesquisa objetivou identificar como alguns temas de EA são abordados nos livros do PNLD. O presente trabalho investigou se os assuntos: (i) utilização de clorofluorcarbonos (CFCs) e destruição da camada de ozônio; (ii) aquecimento global e efeito estufa; (iii) chuva ácida e (iv) água: poluição e tratamento atendem de forma satisfatória, ou seja, se irão na melhor compreensão destes assuntos. A escolha destes itens se justifica pelos conhecimentos químicos que eles envolvem bem como a quantidade de questões que aparecem em concursos públicos e no Exame Nacional do Ensino Médio (ENEM). A elaboração do roteiro de análise foi à ficha de avaliação do GUIA DO LIVRO DIDÁTICO e a pesquisa seguiu referencial teórico de Bardin (2011) em que são criados pelo pesquisador, determinados parâmetros definidos como indicadores, que apresentam o objetivo de direcionar as ideias que serão analisadas. A partir destes indicadores, surgiram três categorias de análise que estão representadas no Quadro 2.

Quadro 2: Indicadores dos LDs associados à categoria de análise.

\begin{tabular}{|c|c|}
\hline Indicadores & Categorias de análise \\
\hline Apresenta o conteúdo de uma forma objetiva? & \multirow[b]{2}{*}{ Explicação teórica do assunto } \\
\hline Mostra a origem do problema? & \\
\hline $\begin{array}{l}\text { Propõe exemplos, experimentos ou textos } \\
\text { explicativos? }\end{array}$ & \multirow{3}{*}{ Compreensão do assunto } \\
\hline $\begin{array}{l}\text { Apresenta o que está sendo feito para resolver ou } \\
\text { minimizar o problema? }\end{array}$ & \\
\hline $\begin{array}{l}\text { Determina as principais consequências para a } \\
\text { sociedade? }\end{array}$ & \\
\hline $\begin{array}{l}\text { O livro apresenta questões pertinentes com o } \\
\text { conteúdo apresentado? }\end{array}$ & \multirow[b]{2}{*}{ Exercícios propostos } \\
\hline $\begin{array}{l}\text { Com base no conteúdo tratado no livro, o aluno } \\
\text { terá condições de resolver os exercícios propostos } \\
\text { pelo autor? }\end{array}$ & \\
\hline
\end{tabular}

\section{RESULTADOS E DISCUSSÕES}

Com o objetivo de averiguar sobre a abordagem dos assuntos ambientais nos livros do PNLD, foi realizada uma análise de cada livro em frente às categorias. Para organizar os resultados o pesquisador utilizou legendas que aparecem nos Quadros 3, 4, 5 e 6. 
Quadro 3: Análise do Livro A

\begin{tabular}{|l|l|l|l|l|}
\hline & \multicolumn{4}{|c|}{ Livro A } \\
\hline Categoria & $\begin{array}{l}\text { Utilização } \\
\text { clorofluorcarbonos } \\
\text { (CFCs) e destruição } \\
\text { da camada de } \\
\text { ozônio. }\end{array}$ & $\begin{array}{l}\text { Aquecimento } \\
\text { global/ } \\
\text { Efeito estufa }\end{array}$ & $\begin{array}{l}\text { Chuva } \\
\text { ácida }\end{array}$ & $\begin{array}{l}\text { Água: } \\
\text { Poluição e } \\
\text { tratamento }\end{array}$ \\
\hline $\begin{array}{l}\text { Explicação } \\
\text { teórica do } \\
\text { assunto }\end{array}$ & AT & AT & AT & AP \\
\hline $\begin{array}{l}\text { Compreensão do } \\
\text { assunto }\end{array}$ & AP & AP & AP & AP \\
\hline Exercícios \\
propostos
\end{tabular}

Legendas: $\mathrm{AT}=$ Atende Totalmente, $\mathrm{AP}=$ Atende Parcialmente, $\mathrm{NA}=$ Não Atende .

Quadro 4: Análise do Livro B

\begin{tabular}{|c|c|c|c|c|}
\hline & Livro B & & & \\
\hline Categoria & $\begin{array}{l}\text { Utilização } \\
\text { clorofluorcarbonos } \\
\text { (CFCs) e destruição } \\
\text { da camada de } \\
\text { ozônio }\end{array}$ & $\begin{array}{l}\text { Aquecimento } \\
\text { global/ } \\
\text { Efeito estufa }\end{array}$ & $\begin{array}{l}\text { Chuva } \\
\text { ácida }\end{array}$ & $\begin{array}{l}\text { Água: } \\
\text { Poluição e } \\
\text { tratamento }\end{array}$ \\
\hline $\begin{array}{l}\text { Explicação teórica } \\
\text { do assunto }\end{array}$ & $\mathrm{AT}$ & $\mathrm{AT}$ & AT & AT \\
\hline $\begin{array}{l}\text { Compreensão do } \\
\text { assunto }\end{array}$ & AP & AP & AT & AP \\
\hline $\begin{array}{l}\text { Exercícios } \\
\text { propostos }\end{array}$ & NA & NA & $\mathrm{AP}$ & AP \\
\hline
\end{tabular}

Legendas: $\mathrm{AT}=$ Atende Totalmente, $\mathrm{AP}=$ Atende Parcialmente, $\mathrm{NA}=$ Não Atende . 
Quadro 4: Análise do Livro C

\begin{tabular}{|l|l|l|l|l|}
\hline & \multicolumn{3}{|c|}{ Livro C } \\
\hline Categoria & $\begin{array}{l}\text { Utilização } \\
\text { clorofluorcarbonos } \\
\text { (CFCs) e destruição } \\
\text { da camada de } \\
\text { ozônio. }\end{array}$ & Aquecimento & Chuva & Água: \\
Efeito estufa & ácida & Poluição e \\
tratamento
\end{tabular}

Legendas: $\mathrm{AT}=$ Atende Totalmente, $\mathrm{AP}=$ Atende Parcialmente, $\mathrm{NA}=$ Não Atende .

Quadro 5: Análise do Livro D

\begin{tabular}{|c|c|c|c|c|}
\hline & \multicolumn{4}{|c|}{ Livro D } \\
\hline Categoria & $\begin{array}{l}\text { Utilização } \\
\text { clorofluorcarbonos } \\
\text { (CFCs) e destruição } \\
\text { da camada de } \\
\text { ozônio }\end{array}$ & $\begin{array}{l}\text { Aquecimento } \\
\text { global/ } \\
\text { Efeito estufa }\end{array}$ & $\begin{array}{l}\text { Chuva } \\
\text { ácida }\end{array}$ & $\begin{array}{l}\text { Água: } \\
\text { Poluição e } \\
\text { tratamento }\end{array}$ \\
\hline $\begin{array}{l}\text { Explicação } \\
\text { teórica do } \\
\text { assunto }\end{array}$ & $\mathrm{AT}$ & $\mathrm{AT}$ & $\mathrm{AT}$ & $\mathrm{AT}$ \\
\hline $\begin{array}{l}\text { Compreensão do } \\
\text { assunto }\end{array}$ & AP & AP & AP & $\mathrm{AT}$ \\
\hline $\begin{array}{l}\text { Exercícios } \\
\text { propostos }\end{array}$ & $\mathrm{AP}$ & $\mathrm{AP}$ & NA & AP \\
\hline
\end{tabular}

Legendas: $\mathrm{AT}=$ Atende Totalmente, $\mathrm{AP}=$ Atende Parcialmente, $\mathrm{NA}=$ Não Atende. 
Quadro 6: Análise do Livro E

\begin{tabular}{|l|l|l|l|l|}
\hline & \multicolumn{3}{|c|}{ Livro E } \\
\hline Categoria & $\begin{array}{l}\text { Utilização } \\
\text { clorofluorcarbonos } \\
\text { (CFCs) e destruição } \\
\text { da camada de ozônio }\end{array}$ & $\begin{array}{l}\text { Aquecimento } \\
\text { global/ } \\
\text { Efeito estufa }\end{array}$ & $\begin{array}{l}\text { Chuva } \\
\text { ácida }\end{array}$ & $\begin{array}{l}\text { Água: } \\
\text { Polução e } \\
\text { tratamento }\end{array}$ \\
\hline $\begin{array}{l}\text { Explicação teórica } \\
\text { do assunto }\end{array}$ & AT & AT & AT & AT \\
\hline $\begin{array}{l}\text { Compreensão do } \\
\text { assunto }\end{array}$ & AP & AP & AP & AT \\
& & & & \\
\hline Exercícios & & NA & NA & AP \\
propostos & & & & \\
\hline
\end{tabular}

Legendas: $\mathrm{AT}=$ Atende Totalmente, $\mathrm{AP}=$ Atende Parcialmente, $\mathrm{NA}=$ Não Atende .

De forma geral a análise mostra que os LDs apresentam uma sequencia didática sobre os assuntos, desde a inserção do tema de acordo com o volume destinado à série do Ensino Médio. Por essa razão na categoria que analisa a explicação teórica do assunto, foram considerados satisfatórios e atentem totalmente à explicação tanto para o professor, quanto para o aluno. $\mathrm{O}$ livro $\mathrm{C}$ foi o único considerado nesta categoria como $\mathrm{AP}$, no tema chuva ácida, pois as abordagens ao tema foram mais direcionadas ao aquecimento global do que à chuva ácida. O livro A recebe a mesma caracterização no tema água: poluição e tratamento, por não fazer uma relação dos processos físicos de separação aos processos de tratamento de águas como os outros fazem, importante relação por mostrar uma aplicação em algo tão importante para a vida que é a água.

De forma geral, os autores iniciam mostrando o fenômeno e fazendo uso de reações químicas para ilustrar a teoria, a diferença está no aprofundamento e nos meios escolhidos para iniciar a explanação sobre o tema.

Neste ponto os livros B, C e D, mostram diferentes formas de iniciar a abordagem, através do uso de reportagens de sites, jornais ou revistas na introdução do assunto, apresentando uma problematização que pode ser utilizada pelo docente como uma forma de despertar o interesse dos alunos. Na categoria compreensão do assunto, as diferenças quanto ao aprofundamento se tornam mais visíveis, pois os livros citam os problemas ambientais para a sociedade, por exemplo, sobre uso de CFC e destruição da camada de ozônio, todos falam que a radiação causa problemas à saúde humana, entretanto não especificam o que é a radiação ultravioleta. $O$ único que sugere as diferenças entre estas radiações é o livro D, definindo o que é UV-A, UV-B e UV-C. Sobre substitutos aos CFCs, os que citam não justificam. O livro B, no tema chuva ácida, apresentou um diferencial em relação aos outros, na compreensão do assunto, por ir além das citações sobre os problemas gerados pela chuva ácida, mostrou as reações que ocorrem além de figuras ilustrativas, ao contrário do livro $C$, que em chuva ácida não apresenta nada além do básico inicial, origem e o que é o problema. Em contra partida o mesmo livro atende totalmente aos temas aquecimento global e água, sobre aquecimento global, é considerado o mais completo, além de apresentar analogias para visualização do efeito, busca mostrar justificativas para a razão pela qual uma molécula apresenta um potencial de aquecimento global. Relaciona as radiações infravermelhas com o cotidiano, e mostra como o ciclo do carbono pode interferir neste processo. No tema água: poluição e 
tratamento o livro C, livro D e o livro E, foram melhores classificados, por relacionar os processos de separação de misturas aos processos de tratamento de águas, apresentando sugestões de experimentos ao docente, embora a parte de tratamento de esgotos seja mostrada de forma superficial em comparação ao tratamento que ocorre nas estações de tratamento de águas (ETA) para o consumo doméstico.

A categoria que apresentou maiores diferenças foi a de exercícios propostos onde os LDs que receberam a classificação NA, não apresentam questões que colaboram para um reforço do conteúdo trabalhado, pelo fato de que estão mais associadas a conteúdos pré-requisitos como, por exemplo: funções inorgânicas, processos físicos de separação de misturas do que ao problema ambiental.

Os que apresentaram a legenda AP apresentam questões que englobam o problema, embora em pequena quantidade. O livro D, sugere a resolução de questões discursivas através da denominação: PENSE, DEBATA, ENTENDA, além de realizar uma retomada de conceitos, propõe questões que sugerem a possibilidade de discussões sobre o tema.

\section{CONCLUSÕES}

Com base na análise realizada nos livros didáticos do PNLD, para assuntos da temática ambiental, observamos que existe uma preocupação por parte dos autores em inserir nas suas obras estes assuntos, embora alguns livros não apresentem uma abordagem completa em um determinado assunto, compensando mais em outro. Isto é compreensível, já que as obras são destinadas ao Ensino Médio, no qual o conteúdo deve ser abordado de uma forma objetiva e nenhum livro é totalmente completo em todos os conteúdos, mesmo quando classificado com a legenda AT. Esta denominação indica que o livro na visão do pesquisador atende de forma satisfatória, pode apresentar alguns pontos incompletos, entretanto estes podem ser mediados pelo professor, não prejudicarão o todo. Logo dos 5 livros disponibilizados pelo PNLD qualquer um atende ao professor, entretanto é importante salientar que a escolha dele levar em consideração a postura do docente. Se o professor tem maior interesse em carga de conteúdo teórico, os livros A e E são mais indicados, por apresentarem uma abordagem mais centrada nas teorias. Os livros C e B, apresentam um enfoque mais dinâmico, com muitos textos que incitam uma discussão, e por isso são mais indicados a professores que buscam uma maior interação com os discentes frente ao tema, para discutir e complementar ideias. O livro D, tem um enfoque mais voltado para a cidadania, onde as temáticas são amparadas por reflexões que convergem para o cotidiano dos alunos. É importante salientar que alguns assuntos que são pré-requisitos muitas vezes não estão no volume destinado à série (por exemplo, o livro A apresenta no volume 2, destinado ao $2^{\circ}$ ano do Ensino Médio a reação do clorofluorcarboneto com o ozônio, embora cloroflúorcarboneto, seja conteúdo do $3^{\circ}$ ano do Ensino Médio), por isso é fundamental a presença do professor para a contextualização dos temas, e para que o conhecimento não seja visto como algo fragmentado, mas como algo contínuo.

\section{REFERÊNCIAS}

BARDIN, L. Análise de Conteúdo. Edição Revista e Ampliada, Edições 70, 2011.

CUBA, M. A. Educação Ambiental nas escolas. ECCOM, v. 1, nº 2, jul/dez, 2010.

CURSinO, A. C T.; SOUZA, R. T.; HARACEMIV, S. M. C.; BARBOZA, L. M. V. Análise do livro didático "Folhas" no Ensino de Química. In: X VI Encontro de Química da Região Sul (16-SBQ Sul), Anais..., Blumenau, 2008.

EDUCAÇÃO NA MÍDIA. Opinião: o papel do livro didático. Disponível em: http://www.todospelaeducacao.org.br/comunicacao-e-midia/educacao-na-midia/26006/opiniao-o-papel-do-livro-didatico/. Em 27 de fevereiro de 2013. Acessado em 27/01/2014

FRISON, M. D, et al. Livro didático como instrumento de apoio para a construção de propostas de Ensino de Ciências Naturais. Encontro Nacional de Pesquisa em Educação em Ciências. Florianópolis, novembro de 2009. 
GUIA DO LIVRO DIDÁTICO: Disponível em: http://www.fnde.gov.br/programas/livro-didatico/guiado-livro/item/2988-guia-pnld-2012-ensino-m\%C3\%A9dio.

JACOBI, P. Educação Ambiental, cidadania e sustentabilidade, Cadernos de pesquisa, n. 118, p. 189 - 205, São Paulo, 2003.

LISBOA, J. C. Ser Protagonista - Química $1^{\circ}$ ano - Ensino Médio. Edições SM, volume 1, São Paulo, 2010. Ser Protagonista - Química $2^{\circ}$ ano - Ensino Médio. Edições SM, volume 2, São Paulo, 2010. Ser Protagonista - Química $3^{\circ}$ ano - Ensino Médio. Edições SM, volume 3, São Paulo, 2010.

MAIA, J. de O, et al. O Livro Didático de Química nas Concepções de Professores de Química do Ensino Médio da Região Sul da Bahia. Química Nova na Escola, vol. 33, Nº 2, maio 2011.

MANTOVANI, K. P. O programa Nacional do Livro Didático - PNLD Impactos na Qualidade do Ensino público. Dissertação de Mestrado, USP, 2009.

MIRANDA, S. R; DE LUCA, T. R. O livro de História hoje: um panorama a partir do PNLD. Revista Brasileira de História, vol 24, n 48, são Paulo, 2004.

MINISTÉRIO DO MEIO AMBIENTE. Disponível em : www.protocolodemontreal.org.br/005/00502001. asp?ttCD_CHAVE $=17525>$.

MORTIMER, E. F; MACHADO, A. H. Química: Ensino Médio. Editora Scipione, volume 1, São Paulo, 2011.

. Química: Ensino Médio. Editora Scipione, volume 2, São Paulo, 2011.

Química: Ensino Médio. Editora Scipione, volume 3, São Paulo, 2011.

SANTOS, W; MÓL, G. Química Cidadã. Editora nova geração, volume 1, São Paulo, 2010. Química Cidadã. Editora nova geração, volume 2, São Paulo, 2010. Química Cidadã. Editora nova geração, volume 3, São Paulo, 2010.

REIS, M. Química - Meio ambiente, Cidadania, Tecnologia. FTD, volume 1, São Paulo, 2010. Química - Meio ambiente, Cidadania, Tecnologia. FTD, volume 2, São Paulo, 2010. Química - Meio ambiente, Cidadania, Tecnologia. FTD, volume 3, São Paulo, 2010.

RODRIGUES, M.H. e FREITAS, N.K. O livro didático ao longo do tempo: a forma do conteúdo.Pesquisa, v. 3, p. 26-33, 2008.

PERUZZO, F. F; CANTO, E. L. Química na abordagem do cotidiano - Química geral e Inorgânica. Moderna, volume 1, $4^{\mathrm{a}}$ edição, São Paulo, 2010.

2, 4ª edição, São Paulo, 2010. Química na abordagem do cotidiano - Físico - Química. Moderna, volume volume 3, 4a edição, São Paulo, 2010.

Química na abordagem do cotidiano - Química Orgânica I. Moderna, 